\title{
Prediction of Compressive Strength of Concretes Containing Silica Fume and Styrene-Butadiene Rubber (SBR) with a Mathematical Model
}

\author{
M. Shafieyzadeh* \\ (Received January 12, 2013, Accepted August 26, 2013, Published online September 10, 2013)
}

\begin{abstract}
This paper deals with the interfacial effects of silica fume (SF) and styrene-butadiene rubber (SBR) on compressive strength of concrete. Analyzing the compressive strength results of 32 concrete mixes performed over two water-binder ratios $(0.35,0.45)$, four percentages replacement of SF $(0,5,7.5$, and $10 \%)$ and four percentages of SBR $(0,5,10$, and $15 \%)$ were investigated. The results of the experiments were showed that in $5 \%$ of SBR, compressive strength rises slightly, but when the polymer/binder materials ratio increases, compressive strength of concrete decreases. A mathematical model based on Abrams' law has been proposed for evaluation strength of SF-SBR concretes. The proposed model provides the opportunity to predict the compressive strength based on time of curing in water $(t)$, and water, SF and SBR to binder materials ratios that they are shown with $(w / b),(s)$ and $(p)$. This understanding model might serve as useful guides for commixture concrete admixtures containing of SF and SBR. The accuracy of the proposed model is investigated. Good agreements between them are observed.
\end{abstract}

Keywords: concrete, silica fume, SBR, compressive strength, mathematical modeling.

\section{Introduction}

Compressive strength of concrete is affected by many factors, such as cement composition and fineness, water-tocement ratio, aggregate, age and temperature of curing. There is as yet no such formula (mathematical model) that could reproduce the effects of all these factors adequately in a quantitative manner, primarily due to a high number of variables (Zelic et al. 2004).

Abrams' water-cement ratio law in 1918 is still considered as a milestone in the history of concrete technology, it is accepted that the largest single factor that governs the strength of concrete is the water to cement ratio. Originally, concrete was made by mixing cement, aggregates and water, and use of admixtures was unknown. The only cementation material was cement. The present-day, new-generation concretes contain mineral admixtures and latexes for a variety of reasons. These materials increase abrasion strength or durability and decrease permeability (Bhikshma et al. 2009; Rozenbaum et al. 2005; Wang et al. 2005; Bhanjaa and Sengupta 2003), and Abrams' formulation needs to be modified or the validity of this relationship for concrete with

Department of Civil Engineering, Shahid Rajaee Teacher Training University, Tehran, Iran.

*Corresponding Author;

E-mail: shafiey_zadeh@yahoo.com

Copyright ( $)$ The Author(s) 2013. This article is published

with open access at Springerlink.com supplementary materials (silica fume (SF), styrene-butadiene rubber (SBR), etc.) should be investigated. The more knowledge be available about the concrete composition versus strength relationship, the better the nature of concrete is understood and how to optimize the concrete mixture.

Silica fume reduces the workability of fresh concrete due to its very specific surface area. It improves a lot of properties of hardened concrete (Bhikshma et al. 2009). SBR latex can reduce water binder ratio, effectively enhance both flexural strength and tensile strength but reduces compressive strength. The previous researches showed that SBRmodified mortars had good mechanical properties and frost resistance (Rozenbaum et al. 2005; Wang et al. 2005). Some researchers have indicated that there is a great potential of combined usage of SF and SBR latex in the increase in the performance of the concrete properties (Rossignol 2009).

Two different ways of adding polymers to cement composites have been described (Barluenga 2004):

1. Keeping the water-to-cement ratio $(w / c)$ constant to obtain a similar hydration of the cement paste.

2. Fitting the consistency of the composite, by adjusting the $w / c$.

In this research, the water to binder ratio is constant $(0.35$, 0.45 ) and the effects of SBR emulsion and SF on fluidity and compressive strength of concrete are investigated and a relationship between compressive strength of concrete with the ratios of polymer, SF, water to binder materials and time of curing in water is proposed. By the way, using mathematical models to take and describe experiences from experimental data 
of concrete mixes behaviors are most reliable, accurate, scientific, and applicable recommended methods.

\section{Experimental Work}

\subsection{Properties of Materials}

The materials used in this research were: Ordinary Portland cement (Type 1) produced by Tehran Factory, and SF, a by-product of the ferrosilicon Deligan Factory.

Coarse aggregate with a maximum particle size of $17 \mathrm{~mm}$ and fine aggregate with a 3.01 finesse modulus were used in the experiment. The specific gravity and water absorption of coarse and fine aggregates were 2.55 and $1.6 \%, 2.25$ and $2.4 \%$, respectively. A water reducer agent with the commercial name of Gelenium 110p from Iranian BASF Construction Chemicals was used to adjust the workability of the concrete mixtures.

The polymer latex used was SBR latex with commercial name of Rheomix 141p from Iranian BASF Construction Chemicals. The properties of SBR latex is presented in Table 1.

\subsection{Testing Program and Procedure}

In this research, Cubes $150 \times 150 \times 150 \mathrm{~mm}$ were cast for compressive strength test. Before casting, coarse aggregate, sand and mixture of water and SF were mixed first. Then, cement, SBR latex and rest water together with superplasticizer were put in the mixer and completely mixed.

The mixed concrete was cast in molds to make specimens, and compacted by mechanical vibration. The specimens were demoded after 1 day. Compressive strength of specimens was measured at three mixed curing systems:

1. 7 days immersed in $20 \pm 2{ }^{\circ} \mathrm{C}$ water and then cured in air at $20 \pm 2{ }^{\circ} \mathrm{C}$ with $20 \pm 10 \%$ of relative humidity for 53 days (7W53D).

2. 14 days immersed in $20 \pm 2{ }^{\circ} \mathrm{C}$ water and then cured in air at $20 \pm 2{ }^{\circ} \mathrm{C}$ with $20 \pm 10 \%$ of relative humidity for 46 days (14W46D).

3. 28 days immersed in $20 \pm 2{ }^{\circ} \mathrm{C}$ water and then cured in air at $20 \pm 2{ }^{\circ} \mathrm{C}$ with $20 \pm 10 \%$ of relative humidity for 32 days (28W32D).

Cement hydration process is retarded by the polymer and surfactants. This is visible especially in the compressive strength (Beeldens et al. 2005).

The cement hydration and polymer film in the modified concretes develop with prolongation cured age, which results in enhanced strength (Wang et al. 2005). Although, the slope of increasing compressive strength of polymer modified concrete declines from 28 to 90 days (Chen and Liu 2007).

Also, combination of wet and dry curing is effective for the strength development of the polymer-modified concretes. A co-matrix is formed by both processes (Jun et al. 2003).
The compressive strength was determined according to BS standard 1881 (Table 2). The loading rate was $0.3 \mathrm{MPa} / \mathrm{s}$.

\section{Test Results and Discussion}

\subsection{Effects of SF and SBR on Fluidity of Concrete}

Silica fume decreases fluidity of concrete but SBR increases fluidity of concrete. Adding of $15 \%$ of SBR to samples with water to binder materials ratio 0.45 induces self-compacting concrete (concrete with slump of $150 \mathrm{~mm}$ ). The effect of SBR in increasing fluidity of concrete is more than the decreasing effect of SF in fluidity (Table 2).

\subsection{Effects of SBR on Compressive Strength}

In polymer-cement ratio (5\%), the compressive strength of modified samples was equal and even slightly higher than that of the no polymer samples (Fig. 1). The filling effect of polymer may be cause increasing a little of Compressive strength. The compressive strength is mostly influenced by the bonding forces generated by hydration reaction of cement (Hwang and Ko 2008; Wu et al. 2002; Hwang et al. 2008), and a little of increasing is observed. It seems at polymer-cement ratio $5 \%$; the continuity of polymer film is only present through small tiny bridges on a limited number of spots. Although, structure between the polymer film and cement hydrates is developed in polymer-cement ratio $(10 \%)$, but compressive strength of concrete is decreased in comparison no polymer concrete. In other words, inclusion of SBR latex in concrete produces with decrease of compressive strength, due to a lower mechanical capacity of polymer film with regard to cement paste.

\subsection{Effects of SF on Compressive Strength}

A significant improvement in compressive strength of concrete is observed because of the high pozzolanic activity and void filling ability of SF. The chemical phase consists of the pozzolanic reaction that transforms the weak calcium hydroxide crystals into the strong calcium silicate hydrate gel. The results of these actions of SF provide significant improvements in compressive strength (Bhanja and Sengupta 2005; Katkhuda et al. 2009; Biswal and Sadangi 2010). The compressive strength of SF concrete continuously is increased with respect to reference concrete and reached a maximum value of $7.5 \%$ replacement level (Fig. 2).

\subsection{Interaction Effects of SF and SBR on Compressive Strength of Concrete}

When the ratio of polymer/binder is certain, the amount of SF affects strength of concrete. The percentage of SF that optimizes compressive strength remains $7.5 \%$ (Fig. 3). In a

Table 1 Properties of SBR.

\begin{tabular}{c|c|c|c}
\hline Density $\left(\mathrm{g} / \mathrm{cm}^{3}\right)$ & Mean particle size $(\mu)$ & Butadiene content & $\mathrm{pH}$ \\
\hline \hline 1.01 & 0.17 & $40 \%$ & 10.5 \\
\hline
\end{tabular}


Table 2 Details of mix proportions.

\begin{tabular}{|c|c|c|c|c|c|c|c|c|}
\hline \multirow{2}{*}{$\begin{array}{l}\text { Water } \\
\left(1 / \mathrm{m}^{3}\right) \\
\end{array}$} & \multirow{2}{*}{$\begin{array}{r}\text { SBR } \\
\left(1 / \mathrm{m}^{3}\right)\end{array}$} & \multirow{2}{*}{$\begin{array}{c}\text { Silica fume } \\
\left(\mathrm{kg} / \mathrm{m}^{3}\right)\end{array}$} & \multirow{2}{*}{$\begin{array}{l}\text { Cement } \\
\left(\mathrm{kg} / \mathrm{m}^{3}\right)\end{array}$} & \multirow{2}{*}{$\begin{array}{c}\mathrm{SP} \\
\left(1 / \mathrm{m}^{3}\right)\end{array}$} & \multirow{2}{*}{$\begin{array}{c}\text { Slump } \\
(\mathrm{mm})\end{array}$} & \multicolumn{3}{|c|}{ Compressive strength $(\mathrm{MPa})$} \\
\hline & & & & & & 7W53D & 14W46D & 28W32D \\
\hline 180 & 0 & 0 & 400 & 2 & 50 & 25.2 & 27.8 & 30.9 \\
\hline 180 & 0 & 20 & 380 & 2 & 40 & 27.9 & 30.1 & 32.8 \\
\hline 180 & 0 & 30 & 370 & 2 & 30 & 30.6 & 32.7 & 34.2 \\
\hline 180 & 0 & 40 & 360 & 2 & 25 & 29.6 & 31.7 & 33.3 \\
\hline 168 & 20 & 0 & 400 & 0 & 35 & 26.6 & 29.8 & 32.4 \\
\hline 168 & 20 & 20 & 380 & 0 & 25 & 29.1 & 31.2 & 34 \\
\hline 168 & 20 & 30 & 370 & 2 & 90 & 27.6 & 29.4 & 32.2 \\
\hline 168 & 20 & 40 & 360 & 2 & 80 & 26.3 & 28.4 & 31.5 \\
\hline 156 & 40 & 0 & 400 & 0 & 90 & 24 & 26.8 & 29.2 \\
\hline 156 & 40 & 20 & 380 & 0 & 85 & 26.5 & 29.2 & 31.8 \\
\hline 156 & 40 & 30 & 370 & 0 & 80 & 28.6 & 30.7 & 33.1 \\
\hline 156 & 40 & 40 & 360 & 0 & 75 & 27.4 & 29.6 & 32.4 \\
\hline 144 & 60 & 0 & 400 & 0 & 160 & 21.5 & 24.1 & 26.7 \\
\hline 144 & 60 & 20 & 380 & 0 & 155 & 23.9 & 26.9 & 29.5 \\
\hline 144 & 60 & 30 & 370 & 0 & 155 & 26.4 & 28.8 & 31.6 \\
\hline 144 & 60 & 40 & 360 & 0 & 150 & 24.6 & 27.5 & 30.2 \\
\hline 140 & 0 & 0 & 400 & 3 & 80 & 31.8 & 36 & 40.4 \\
\hline 140 & 0 & 20 & 380 & 3.2 & 70 & 33.8 & 37.1 & 42.5 \\
\hline 140 & 0 & 30 & 370 & 3.2 & 70 & 35.9 & 40.4 & 45.1 \\
\hline 140 & 0 & 40 & 360 & 3.4 & 60 & 34.5 & 38.4 & 43.3 \\
\hline 128 & 20 & 0 & 400 & 2 & 80 & 32.7 & 37 & 41.4 \\
\hline 128 & 20 & 20 & 380 & 2.2 & 70 & 35.1 & 39 & 44.2 \\
\hline 128 & 20 & 30 & 370 & 2.2 & 60 & 37 & 42.4 & 47.5 \\
\hline 128 & 20 & 40 & 360 & 2.4 & 60 & 36.1 & 40.7 & 45.8 \\
\hline 116 & 40 & 0 & 400 & 1 & 90 & 30.2 & 32.6 & 37.3 \\
\hline 116 & 40 & 20 & 380 & 1.2 & 80 & 32.3 & 36.1 & 40.2 \\
\hline 116 & 40 & 30 & 370 & 1.2 & 70 & 34.2 & 37.4 & 42.8 \\
\hline 116 & 40 & 40 & 360 & 1.4 & 60 & 33.5 & 35.8 & 42.2 \\
\hline 104 & 60 & 0 & 400 & 0 & 50 & 27 & 29.4 & 34.1 \\
\hline 104 & 60 & 20 & 380 & 0 & 60 & 29.3 & 31.4 & 36.1 \\
\hline 104 & 60 & 30 & 370 & 0 & 65 & 30.2 & 32.7 & 38.2 \\
\hline 104 & 60 & 40 & 360 & 0 & 70 & 30.2 & 32.2 & 37.8 \\
\hline
\end{tabular}

few samples, a local decrease in compressive strength is observed in $5 \%$ polymer (Fig. 4). In making of these samples percentage of superplastysizer in 0 and $5 \%$ polymer were constantly considered. The cavitations of superplastysizer induce a decrease in compressive strength of these samples.
3.5 Investigation of Main Effects and Interaction Effects of Factors in Compressive Strength

The main effects of each factor are shown in Fig. 5. It is observed that decreasing of water to binder materials $(w / b)$ from 0.45 to 0.35 increases compressive strength about $26 \%$. Averagely, $7.5 \%$ of replacements of SF increases 


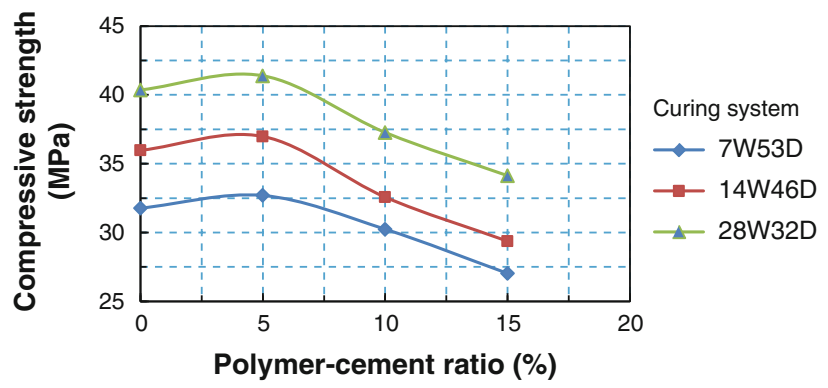

Fig. 1 Effect of polymer-cement ratio on the compressive strength of concrete ( $w / c=0.35$ and $0 \%$ silica fume) .

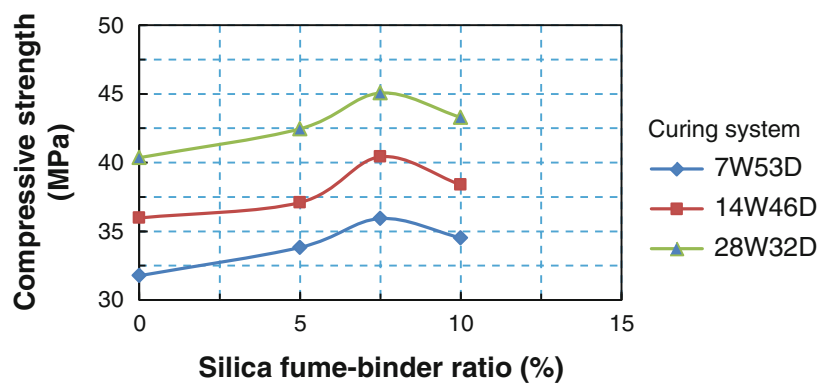

Fig. 2 Effect of silica fume-binder ratio on the compressive strength of concrete ( $w / b=0.35$ and $0 \%$ SBR).

compressive strength about $13 \%$. Also, adding $15 \%$ of SBR decreases compressive strength about $14 \%$.

A single diagram of interaction effects of factors in compressive strength is shown in Fig. 6. Parallel lines in an interaction diagram indicate there is no interaction effect between variables. The greater of the lines departure from the parallel state indicates the higher degree of interaction, in this situation, the response at a factor level depends upon the levels of other factors. Therefore, there is no interaction effect between SBR and SF. Although, a decrease in compressive strength of samples with 5\% SBR and 7.5-10\% $\mathrm{SF}$ in water to binder ratio 0.45 is happening. (In making of these samples (Table 3 ), the ratio of superplastysizer is kept constant.)

\section{Mathematical Model}

The results obtained from an experiment can be shown by a mathematical model. Here, the primary factors that affected the compressive strength of concrete are the ratios of water, SBR, SF to binder materials and time of curing in water. (In modeling, from effects of superplastysizer on compressive strength is neglected.)

Relationship compressive strength with main effective factors can be determined by regression. But before regression needs to determine each factor how influence in compressive strength.

As per the classical formulation of Abrams' law, there exists an inverse relationship between the compressive

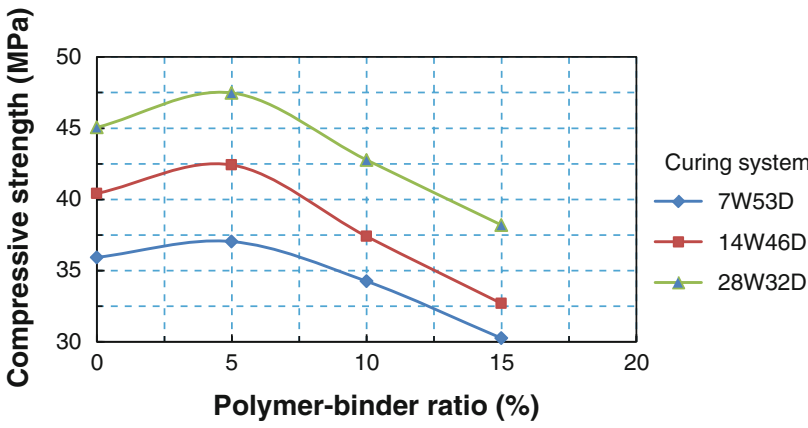

Fig. 3 Effect of polymer-binder materials ratio on the compressive strength of polymer modified concrete $(w / b=0.35$ and $7.5 \%$ silica fume).

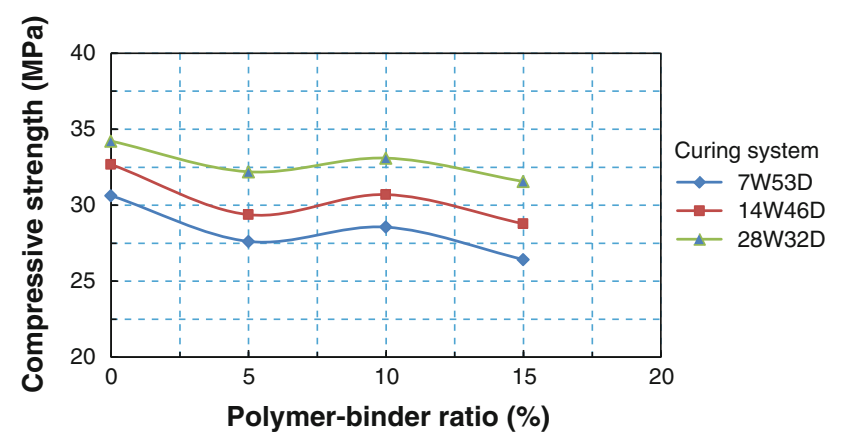

Fig. 4 Effect of polymer-binder ratio on the compressive strength of polymer modified concrete $(w / b=0.45$ and $7.5 \%$ silica fume).

strength and water to cement ratio of concrete (Popovics 1998). Abrams' equation can be showed by:

$$
f=\frac{A}{B^{\left(\frac{w}{c}\right)}}
$$

$A, B$ are constant coefficients and $\left(\frac{w}{c}\right)$ is the ratio of water to cement.

A lot of researchers introduced relationship between compressive strength and time of curing in water with a logarithmic equation by (Popovics 1998): ( $a, b$ are constant coefficients.)

$$
f=a \times \log (t)+b
$$

Bihanja and Khan (Bhanja and Sengupta 2002; Iqbal khan 2009) proposed power equations for the effect of SF on compressive strength of concrete. Bhanja (Bhanja and Sengupta 2002) proposed a three degree function for prediction compressive strength of SF concrete. When the percentage of replacement of SF is less than 10 , the relationship between compressive strength and SF can be considered with a parabola curve. (Base on Bhanja's relationship, the maximum error will be less than $2.5 \%$.)

Although, Barleonga used linear approximation to show the relationship between compressive strength and SBR \% 


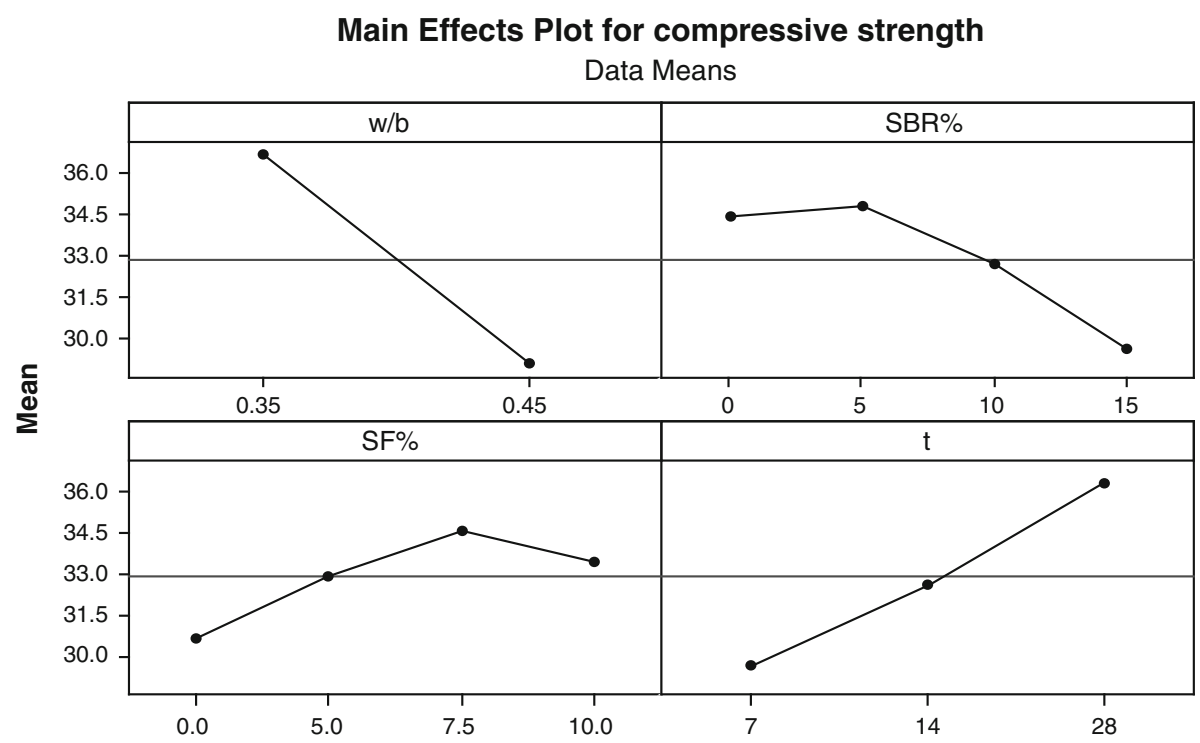

Fig. 5 Main effects of diagram for compressive strength.

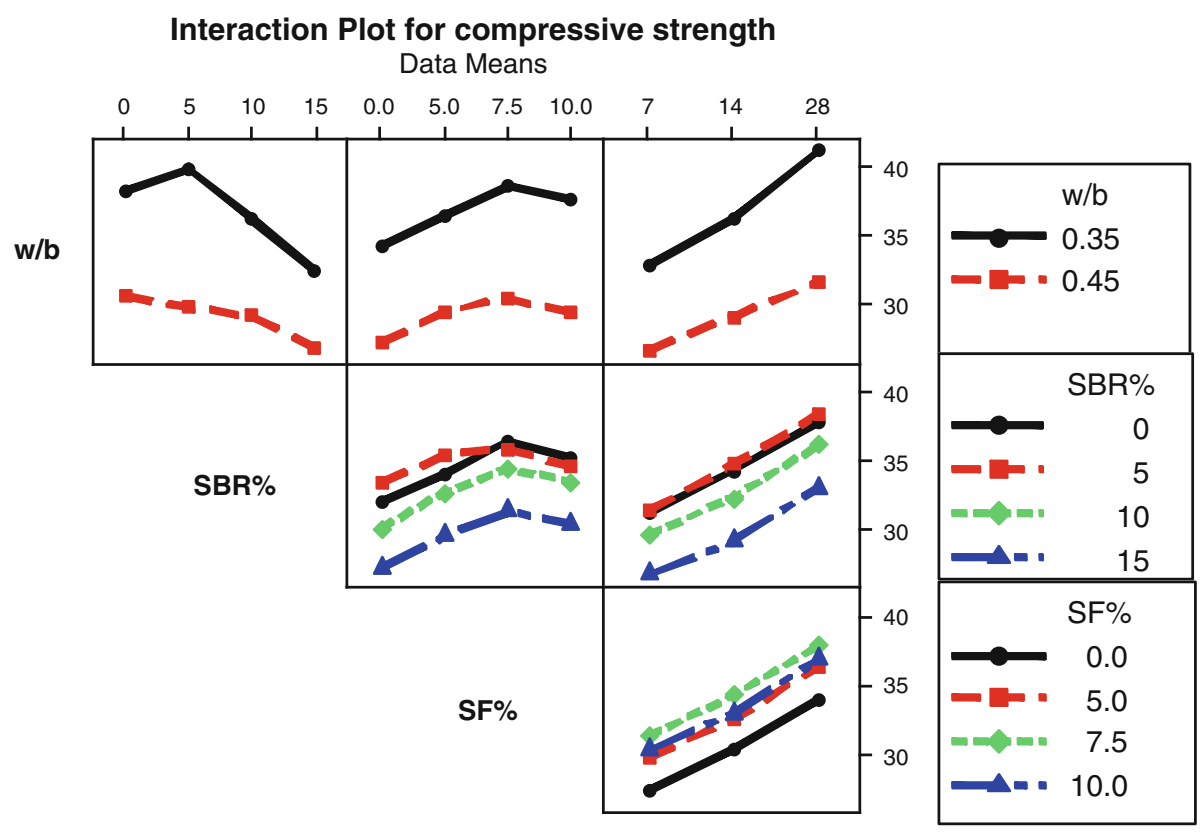

t

Fig. 6 Interaction effects of diagram for compressive strength.

Table 3 Numeric values of the rate constants from above equation.

\begin{tabular}{c|c|c|c|c}
\hline$A$ & $B$ & $C$ & $D$ & $E$ \\
\hline \hline 2.637 & 0.999 & 0.98 & 1.005 & 0.977 \\
\hline
\end{tabular}

but, in mixed curing system, a little of increasing of compressive strength is observed in $5 \%$ of SBR and a $2^{\circ}$ parabolic can be appropriate to show the effect of SBR in compressive strength. In Figs. 7, 8, and 9 relationship between the compressive strength with each factor is determined.

The relationship between compressive strength with considered variables may be represented by:

$$
\begin{aligned}
f_{\mathrm{c}} & =\frac{A}{\mathrm{~B}^{\left(\frac{w}{b}\right)}} \times(11.04 \times \log (t)+20.22)^{C} \\
& \times\left(-525.9 s^{2}+83.81 s+30.54\right)^{D} \\
& \times\left(-346 p^{2}+18.72 p+34.49\right)^{E}
\end{aligned}
$$

where $f_{c}$ is the compressive strength (MPa), $w / b$ is the ratio of water to binder materials, $t$ is time of curing in water 


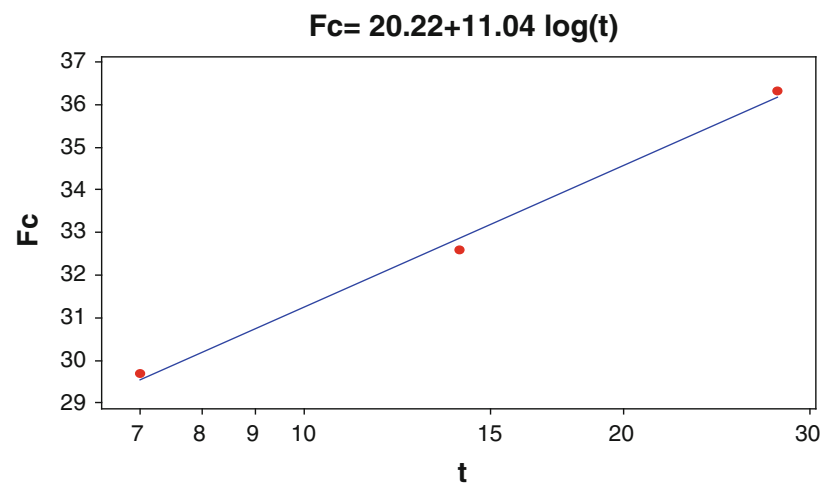

Fig. 7 Relationship between compressive strength with time of curing in water (days).

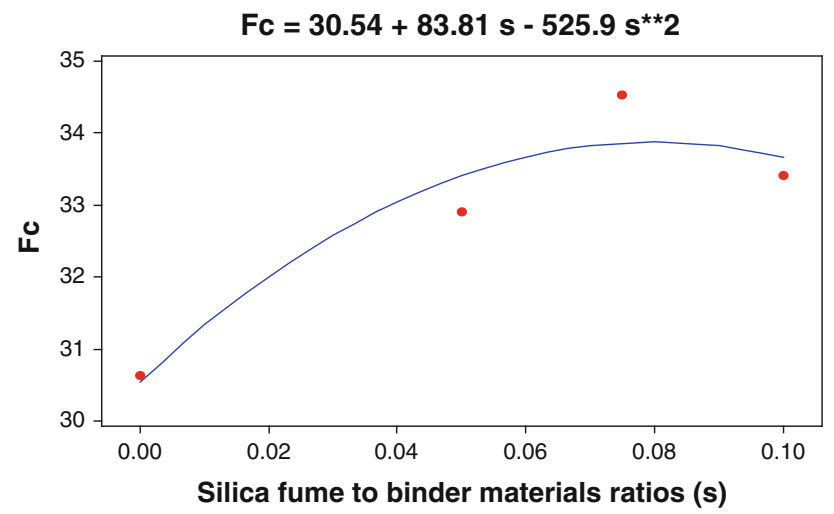

Fig. 8 Relationship between compressive strength and Silica fume to binder materials ratios $(s)$.

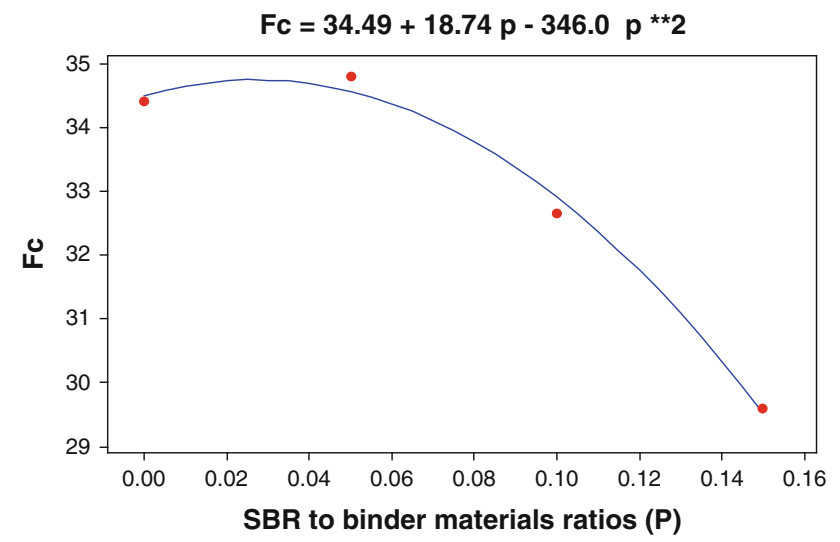

Fig. 9 Relationship between compressive strength and SBR to binder materials ratios $(p)$.

(day), $s$ is the ratio of SF to binder materials and $p$ is the ratio of SBR polymer to binder materials. $A, B, C, D$ and $E$ are constant coefficients. The above equation can be written in the following form:

$$
\begin{aligned}
\log \left(f_{c}\right) & =\log (A)-\log B \times \frac{w}{b}+C \\
& \times \log (11.04 \times \log (t)+20.22)+D \\
& \times \log \left(-525.9 s^{2}+83.81 s+30.54\right) \\
& +E \times \log \left(-346 p^{2}+18.72 p+34.49\right)
\end{aligned}
$$

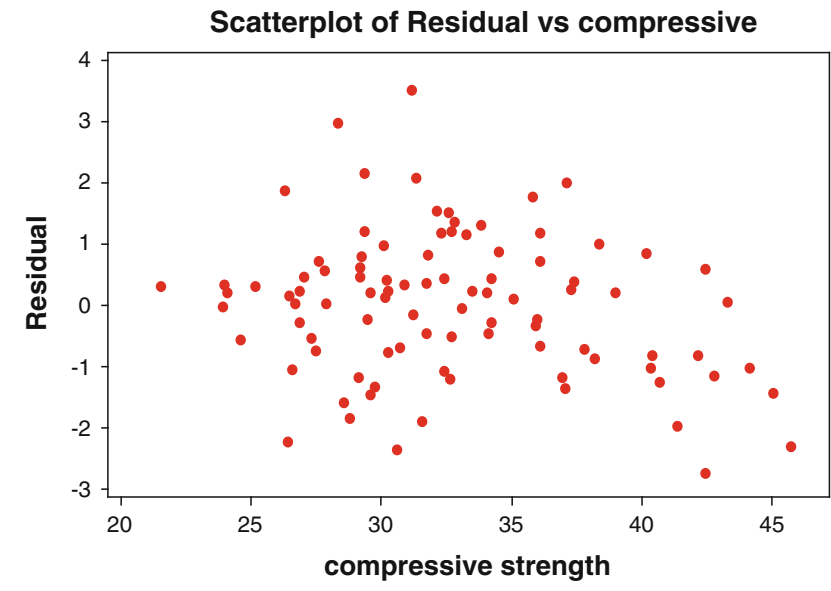

Fig. 10 Diagram of residuals for compressive strength.

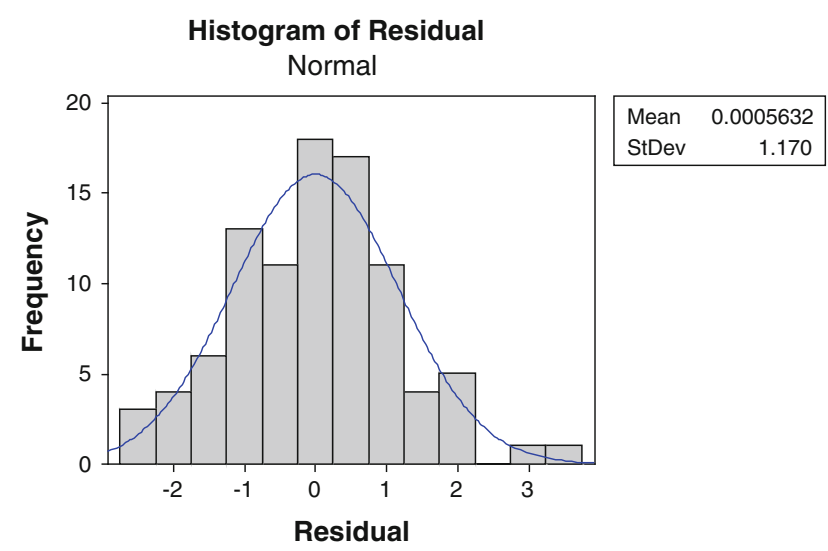

Fig. 11 Histogram of residuals for compressive strength.

where $A, B, C, D$ and $E$ can be determined with multiple linear regressions. The values of these coefficients are shown in Table 3. The value of multiple correlation coefficients $(r)$ has been obtained as 0.95 .

With replacement of one to coefficients that are near one and some simplification, the following equation is obtained.

$$
\begin{aligned}
f_{c} & =\frac{49.2}{10^{\left(\frac{w}{b}\right)}} \times(0.546 \times \log (t)+1) \\
& \times\left(-17.22 s^{2}+2.74 s+1\right)\left(-10 p^{2}+0.54 p+1\right)
\end{aligned}
$$

For investigation of the accuracy of above equation, diagram of residuals (the difference of observed and fitted values) for compressive strength has been drawn (Fig. 10). The diagram of residuals for compressive strength shows that the maximum error percent of prediction of compressive strength is about $10 \%$. Although, the distribution residuals does not completely obey the normal distribution but the mean and maximum values of histogram of residuals is located near zero (Fig. 11).

\section{Conclusion}

Results can be summarized as follows:

1. The effect of SBR in increasing of fluidity of concrete is greater than the effect of SF in decreasing of fluidity of concrete. 
2. In constant water to binder ratio and combined curing system, the compressive strength of concrete in $5 \%$ SBR rises slightly, but when polymer/binder ratio increases, the compressive strength of concrete decreases.

3. Cement replacement up to $7.5 \%$ with SF leads to increase in compressive strength.

4. The decrease of compressive strength is compensated by the reduction of $w / b$ due to the plasticizer effect of SBR. Both phenomena together remain compressive strength approximately constant.

5. The percentage of SF that optimizes the compressive strength with adding SBR doesn't change.

6. Abram's law with some modification is applicable to the compressive strength of concretes contain of SF and SBR. Also, according to main effects of diagram can be proposed the following equation:

$$
\begin{aligned}
f_{c}= & \frac{49.2}{10^{\left(\frac{w}{b}\right)}} \times(0.546 \times \log (t)+1) \\
& \times\left(-17.22 s^{2}+2.74 s+1\right)\left(-10 p^{2}+0.54 p+1\right)
\end{aligned}
$$

The proposed model provides the opportunity to predict the compressive strength based on the time of curing in water $(t)$, and water, SF and SBR to binder materials ratios that they are shown with $(w / b),(s)$ and $(p)$, briefly.

\section{Open Access}

This article is distributed under the terms of the Creative Commons Attribution License which permits any use, distribution, and reproduction in any medium, provided the original author(s) and the source are credited.

\section{References}

Barluenga, G., \& Hernández-Olivares, F. (2004). SBR latex modified mortar rheology and mechanical behavior. Cement and Concrete Research, 34, 527-535.

Beeldens, A., Van Gemert, D., Schorn, H., Ohama, Y., \& Czarnecki, L. (2005). From microstructure to macrostructure: An integrated model of structure formation in polymer-modified concrete. Materials and Structures, 38, 601-607.

Bhanja, S., \& Sengupta, B. (2002). Investigations on the compressive strength of silica fume concrete using statistical methods. Cement and Concrete Research, 32, 1391-1394.

Bhanja, S., \& Sengupta, B. (2005). Influence of silica fume on the tensile strength of concrete. Cement and Concrete Research, 35(2005), 743-747.

Bhanjaa, S., \& Sengupta, B. (2003). Modified water-cement ratio law for silica fume concretes. Cement and Concrete Research, 33, 447-450.
Bhikshma, V., Nitturkar, K., \& Venkatesham, Y. (2009). Investigations on mechanical properties of high strength silica fume concrete. Asian Journal of Civil Engineering Building and Housing, 10(3), 335-346.

Biswal, K. C., \& Sadang, S. C. (2010). Effect of superplasticizer and silica fume on properties of concrete. In Proceedings of International Conference on Advances in Civil Engineering.

Chen, B., \& Liu, J. (2007). Mechanical properties of polymermodified concretes containing expanded polystyrene beads. Construction and Building Materials, 21, 7-11.

Hwang, E. H., \& Ko, Y. S. (2008). Comparison of mechanical and physical properties of SBR-polymer modified mortars using recycled waste materials. Journal of Industrial and Engineering Chemistry, 14, 644-650.

Hwang, E. H., Ko, Y. S., \& Jeon, J. K. (2008). Effect of polymer cement modifiers on mechanical and physical properties of polymer-modified mortar using recycled artificial marble waste fine aggregate. Journal of Industrial and Engineering Chemistry, 14, 265-271.

Iqbal khan, M. (2009). Analytical model for strength prediction of HPC consisting of cementations. Architecture Civil Engineering Environmental, 1, 89-96.

Jun, L., Chang-Wei, X., Xiao-Van, Z., \& Ling, W. (2003). Modification of high performances of polymer cement concrete. Journal of Wuban University of TechnologyMater, 18(1), 61-64.

Katkhuda, H., Hanayneh, B., \& Shatarat, N. (2009). Influence of silica fume on high strength of light weight concrete. World Academy of Science, Engineering and Technology, 58, 781-788.

Popovics, S. (1998). Strength and related properties of concrete a quantitative approach. New York, NY: Wiley.

Rossignol, J. A. (2009). Interfacial interactions in concretes with silica fume and SBR latex. Construction and Building Materials, 23(2009), 817-821.

Rozenbaum, O., Pellenq, R. J. M., \& Van Damme, H. (2005). An experimental and mesocopic lattice simulation study of styrene-butadiene latex-cement composites properties. Materials and Structures, 38, 467-478.

Wang, R., Wang, P. M., \& Li, X. G. (2005). Physical and mechanical properties of styrene-butadiene rubber emulsion modified cement mortars. Cement and Concrete Research, 35, 900-906.

Wu, K. R., Zhang, D., \& Song, J. M. (2002). Properties of polymer-modified cement mortar using pre-enveloping method. Cement and Concrete Research, 32, 425-429.

Zelic, J., Rusic, D., \& Krstulovic, R. (2004). A mathematical model for prediction of compressive strength in cementsilica fume blends. Cement and Concrete Research, 34, 2319-2328. 